\title{
'Wasting time inside my mind': Exploring student pharmacists' perspectives on engaging in mindfulness oriented meditation using concepts from education research
}

\author{
Logan T Murry \& Matthew J Witry (iD \\ The University of lowa College of Pharmacy, lowa City, USA.
}

\section{Keywords}

Mindfulness

Mindfulness Oriented Meditation

Mindfulness-Based Stress Reduction (MBSR)

Stress

Resilience

Pharmacy

Education

\section{Correspondence}

Logan T Murry

Department of Pharmacy Practice and Science

University of lowa College of Pharmacy

lowa City

USA

logan-murry@uiowa.edu

\begin{abstract}
Background: Pharmacy students are subject to high levels of stress. An emerging way student pharmacists and pharmacists have reported managing stress and developing professional resilience is through mindfulness. Objectives: To 1) describe how student pharmacists appraise the threat of stress; and 2) identify student perceptions of mindfulness-oriented meditation (MOM) as a stress management strategy and how MOM may fit in the pharmacy curriculum. Methods: A descriptive qualitative research study was conducted using focus groups comprised of first-year, second-year, and thirdyear pharmacy students at a college of pharmacy within the United States. A facilitation guide based on the study objectives was designed to guide focus group discussion and a basic interpretivist paradigm was used to underpin a phenomenological approach to interpreting the data. Representative quotes were identified by the authors to illustrate the main concepts from the focus groups. Results: In total, fourteen students participated across the three class-year focus groups. Students expressed a general interest in mindfulness, but their interest conflicted with feelings of business and time-constraints. Offering a certificate or other tangible reward made engaging in mindfulness and MOM more appealing. Conclusions: The concepts of the student's academic perspective and learning motivation appear to influence mindfulness interest and reasons for participation. Colleges may need to change their criteria for judgment for wellness initiatives like MOM to be more widely adopted.
\end{abstract}

\section{Introduction}

Pharmacy students are subject to increasing levels of stress, with pharmacy programmes requiring students to juggle challenging courses, each with exams and assignments (Marshall et al., 2008; Beall et al., 2015; Awe et al., 2016; Silva \& Figueiredo-Braga, 2018). Students also allocate time and effort to extracurricular activities, parttime jobs, social lives, and many have family and caregiving responsibilities (Awe et al., 2016; OpokuAcheampong et al., 2017). While stress certainly arises as a response to balancing these external stimuli, stress also can originate from an individual's expectations (Schommer et al., 2019). Striving for perfection and fear of failure have been shown to increase stress among pharmacy students and pharmacists (Schommer et al., 2019). While the jobs obtained following pharmacy licensure are generally well-compensated, many students graduate with high levels of student loan debt, which may contribute to experienced stress (Chisholm-Burns et al., 2017; Schommer et al., 2019). 
The high degree of stress experienced by students combined with feelings of time and resource scarcity (Huijsmans et al., 2019) may result in difficulty developing effective coping mechanisms, finding fulfilment in an individual's personal and professional life, and building resilience (Schommer et al., 2019). Resilience consists of personal characteristics, workplace characteristics, and social networks (Matheson et al., 2016), and can be defined as the dynamic process of dealing with an adversity or personal setback (Luthans, Vogelgesang, \& Lester, 2006). One novel way students and pharmacists reported maintaining satisfaction, fulfilment, and professional resilience was through mindfulness (Schommer et al., 2019). Given the reported use of mindfulness to manage stress and increase resilience, mindfulness oriented meditation (MOM) may be a potentially useful coping mechanism worthy of exploration by pharmacy students (Lamothe et al., 2016; McConville, McAleer, \& Hahne, 2017; Morrison et al., 2017; O'Driscoll et al., 2019).

MOM, while not mainstream, has been gaining popularity due to increased cultural attention surrounding its role in wellness initiatives and the proliferation of web- and smartphone-based tools for guided meditation (Heeter et al., 2017; Economides et al., 2018; Pospos et al., 2018). In general, MOM refers to a deliberate meditative practice where one focuses their mind on a particular physiologic sensation (e.g. breathing) or provides meditative activities to structure the individual practice experience. Practicing MOM facilitates awareness of behavioural patterns and of continuous past- and future-related thoughts and ruminations (Crescentini et al., 2016). Mindfulness-based stress reduction (MBSR), the most studied form of MOM in health professional education, is typically taught as an eight-week programme with in-person instruction and athome practice assignments between sessions (Lamothe et al., 2016). MBSR develops mindfulness, which has been defined as 'paying attention in a particular way: on purpose, in the present moment, non-judgmentally' (KabatZinn, 1994: p.4). Recent evidence suggests MBSR smartphone applications may be effective at reducing stress, anxiety, and improving overall mental health (Morrison et al., 2017; Economides et al., 2018; Pospos et al., 2018; Yang et al., 2018; van der Riet, Levett-Jones, \& Aquino-Russell, 2018). A growing body of literature exists in nursing and medical education for practicing MOM and testing the impact (Lamothe et al., 2016; McConville, McAleer, \& Hahne, 2017; Pospos et al., 2018; van der Riet, Levett-Jones, \& Aquino-Russell, 2018). Additionally, as MOM is an inherently reflective practice, there may be benefits for healthcare professionals in clinical situations (Mantzourani et al., 2019). Reflective practices have shown to be an important component of pharmacy education, encouraging learning from multiple perspectives while developing an appreciation for how knowledge-based curricula intersects with evolving practice settings and clinical skills (Tsingos, BosnicAnticevich, \& Smith, 2014; Mantzourani, et al., 2019). Despite potential benefits, there has been limited exploration of MOM within pharmacy education and practice (O'Driscoll et al., 2017; Pospos et al., 2018; O'Driscoll et al., 2019; Witry, Murry, \& Ray, 2020). Existing explorations of mindfulness in pharmacy education have been conducted in undergraduate academic settings outside of the United States (US) (O'Driscoll et al., 2017; O'Driscoll et al., 2019) receiving recent consideration for inclusion in a doctoral pharmacy curriculum within the US (Witry, Murry, \& Ray, 2020). Currently, little work has been done to evaluate US-based pharmacy student perceptions of mindfulness and MOM as a stressmanagement strategy. Given the high levels of anxiety and depression among students and high rates of burnout among pharmacists (Jones et al. 2017; Durham, Bush, \& Ball, 2018), MOM may be a potential avenue to mitigate the effects of high stress educational and professional settings.

The Transactional Theory of Stress and Coping (TTSC) can be used as a theoretical framework to examine where mindfulness might fit in health professional education as a stress management technique. TTSC, developed by Richard Lazarus, presents stress as a product of a transaction between a person (including multiple systems: cognitive, physiological, affective, psychological, neurological) and the individual's complex environment (Lazarus \& Folkman, 1987). In addition, TTSC categorises stress as acute, episodic, and chronic. The central concept of TTSC explores how an individual appraises a stressor, and how appraisal determines which coping mechanisms will be deployed in an attempt to mitigate particular stressors. Given the current expectations of pharmacy students within the pharmacy curriculum, it can be argued all students are chronically, or at the very least, episodically stressed. Students may differ in how they experience stress, which may influence the coping mechanisms they choose to use, including novel coping mechanisms and resilience building activities such as mindfulness or MOM (Schommer et al., 2019).

The overall aim of this study was to understand the relationship between student stress and their interest in exploring potentially useful coping mechanisms like MOM. 
The objectives of this study were to: 1 ) describe how student pharmacists appraise the threat of stress in their daily life; and 2) identify student perceptions of mindfulness oriented meditation (MOM) as a stress management strategy and how MOM may fit in the pharmacy curriculum.

\section{Methods}

This descriptive qualitative research study took place at a large, research-oriented college of pharmacy located in the US with approximately 100 students per class in the Doctor of Pharmacy (Pharm.D.) programme. In total, the Pharm.D. programme requires a minimum two-years of undergraduate training and prerequisites for admission. The four-year curriculum resulting in a doctoral degree in pharmacy (Pharm.D.) is comprised of five semesters of didactic coursework, followed by experiential education and student-selected elective coursework.

Data were collected from three focus groups conducted with first, second, and third-year pharmacy students to address the primary study aim and study objectives. Focus groups were not conducted with fourth-year students due to advanced experiential education rotations. The rationale for using focus groups was to facilitate a discussion among students. To account for potential variations in the stress experience and to make students feel comfortable, three separate focus groups were scheduled, allowing for homogenous groups of first- (P1), second- (P2), and third-year (P3) pharmacy students to participate. The study was submitted to the IRB/Human Subjects Office, and was granted a 'Non-Human Subjects Research' determination. Given this determination, signed consent documents were not required; however, students were informed that focus groups would be recorded, assured that their names would not be associated with the reported data, and provided with an opportunity to refuse participation. This research did not receive any specific grant from funding agencies in the public, commercial, or not-for-profit sectors.

Students were recruited to participate via email and paper flyers posted around the study college of pharmacy. Website URLs were shortened so students could manually type the link if responding to the flyer. The link directed students to a web-form where they entered their contact information to sign up for a focus group time. Two recruitment emails were sent. A reminder email was sent out days before each focus group. Restricting participants to the same class year was done so students further along in the programme would not dominate the conversation. Food was provided as an incentive for participation.

A focus group guide was designed to address the study objectives in an open and conversational way. Probes were used to add clarification and encourage students to expand on their ideas. The focus group guide (Appendix A) asked participants about their approaches to managing stress in an effort to stimulate discussion. The topic then shifted to mindfulness and MOM. Participants were asked to share their familiarity with these concepts. Next, participants were provided a definition of mindfulness and prompted to react. Lastly, students were asked about the potential role of mindfulness in the pharmacy curriculum. Focus groups were assisted by the primary author and moderated by the senior author. . Discussion occurred following each focus group to document initial impressions. Focus groups were digitally recorded and transcribed.

Data were analysed using a basic interpretivist paradigm, to underpin the phenomenological qualitative data analysis approach facilitated by MAXQDA qualitative data analysis software (VERBI, Berlin, Germany) (Thomas, 2006). Inductive and deductive analysis were performed by the study authors, with inductive analysis performed by independently evaluating focus group transcripts. Deductive analysis was performed by relating consistent inductive themes to existing theory and existing literature to construct theory-driven explanations for student perceptions. First, focus group transcripts were independently analysed and reviewed for initial impressions. Next, descriptive codes and in-vivo codes were applied based on topics and student ideas to provide a general sorting of the data. The code list was revised in an iterative process and developed definitions for the codes. Code summaries were then finalised, and representative quotes were selected. Both authors regularly met throughout the study to discuss data collection, coding, analysis, and reporting. Existing literature was consulted throughout the research process and discussions with colleagues in pharmacy education and education helped to place the findings into a broader context. Sub-themes were assigned to various student pharmacist transcript segments within each emerging theme. These sub-themes are highlighted in the text and included in brackets at the end of each quote. Additionally, specific terminology and phrasing used by student pharmacists that reinforce themes and sub-themes have been underlined in the included transcript text. A member checking discussion was held with three of the focus group participants to get feedback on the overall themes. 
Table I: Themes and quotes not contained in text from focus groups

\begin{tabular}{|c|c|}
\hline Themes & Quotes not contained in text \\
\hline $\begin{array}{l}\text { Variation in stress } \\
\text { experience: Low Stress }\end{array}$ & $\begin{array}{l}\text { I feel like I've, I think hesitant to do it [mindfulness] just cause I'm like, am I really that stressed, like, I quess my only thing would } \\
\text { like...I don't feel like I need it.' [Low Stress] } \\
\text { 'Usually Saturdays I kind of set aside for myself as well. Friday nights and Sunday all day I study. I think it's because that organisation } \\
\text { and that lack of procrastination, that I don't become stressed.' [Low Stress] }\end{array}$ \\
\hline $\begin{array}{l}\text { Variation in stress } \\
\text { experience: High } \\
\text { Stress }\end{array}$ & $\begin{array}{l}\text { I think, because I found out that the first couple of modules I found out that I studied pretty hard and I had a pretty good grip on it } \\
\text { but somehow I didn't do well on the exams for some reason, so I'm still kind of sore from the stress and trying to figure out why my } \\
\text { studying didn't work. I realise okay, so I start to learn how to work around it to try out some new strategies so. I realised the reason } \\
\text { my stress.' [High Stress] } \\
\text { 'I feel like I'm pretty hard on myself. Like if I don't get something productively done during the day, I feel like I've wasted my } \\
\text { time.' [High Stress, Negative Self-talk] } \\
\text { 'It's like, 'Oh I can be...I can not judge other people and be present and open with them, but when I try to do it with myself, it's } \\
\text { hard.' [High Stress, Negative Self-talk] }\end{array}$ \\
\hline $\begin{array}{l}\text { Coping mechanism } \\
\text { appraisal and } \\
\text { expectations in the } \\
\text { academic setting }\end{array}$ & $\begin{array}{l}\text { I listen to music in mornings to get ready, so it's like kind of multitasking, but that's mindless.' [Mindless] } \\
\text { 'I watch a lot of cooking videos on YouTube. Because the food I like, I like making the food that I stress eat.' [High Stress, Unhealthy } \\
\text { Coping] } \\
\text { 'Like the other night before and I ate Oreos and candy bar for dinner, because we were making stuff for Campus and we were baking } \\
\text { these turkey Oreos and, or Oreo turkey, I quess. I actually kept eating them, like anytime there was a broken one I would just eat it. } \\
\text { And after that I'm like, I think I have eaten like } 10 \text { Oreos in like } 10 \text { minutes.' [Mindless, High Stress, Unhealthy Coping] } \\
\text { 'My coping mechanisms don't work very well because I have a lot of projects that seem to be due at one time, I work really hard on } \\
\text { those and then I'm like "Oh, I need a break." But then I....and then it piles up again because I don't feel like doing stuff.' [Ineffective } \\
\text { Coping] }\end{array}$ \\
\hline $\begin{array}{l}\text { Motivation to } \\
\text { participate in } \\
\text { mindfulness: Initial } \\
\text { interest, perceptions, } \\
\text { and misconceptions }\end{array}$ & 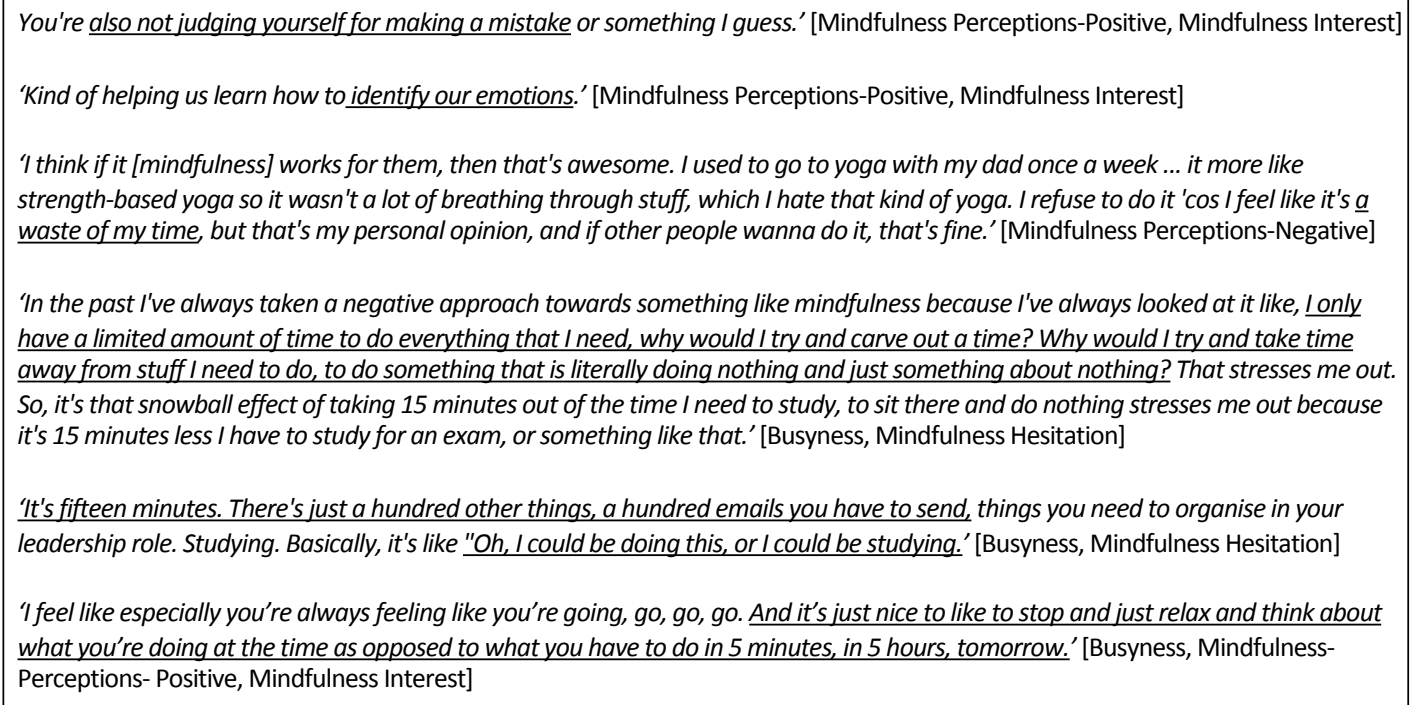 \\
\hline $\begin{array}{l}\text { Motivation to } \\
\text { participate in } \\
\text { mindfulness: } \\
\text { Mindfulness benefit } \\
\text { evaluation and } \\
\text { rationalisation }\end{array}$ & $\begin{array}{l}\text { Marketing it for self-improvement rather than stress reduction.' [Mindfulness Benefit Evaluation and Rationalisation] } \\
\text { 'I think that there would be a lot more interest if we were able to tie it back to what we'll be doing either in school or as a } \\
\text { profession.' [Mindfulness Benefit Evaluation and Rationalisation] } \\
\text { 'Techniques that you can actually practice that are short, quick, something like that that you can use in the profession } \\
\text { too.' [Mindfulness Benefit Evaluation and Rationalisation] } \\
\text { 'A certificate or something that shows I learned this, and I can apply it.' [Mindfulness Benefit Evaluation and Rationalisation] }\end{array}$ \\
\hline
\end{tabular}




\section{Results}

Across the three focus groups, fourteen students participated. For the P1s, six signed up and six attended, for the P2s, eight signed up and six participated, and for the P3s, 6six signed up and two participated. The flow and content richness of the focus groups were similar, and each lasted approximately 45 minutes. Three themes are used to discuss the student experience: 'Variation in stress experience', 'Coping mechanism appraisal and expectations', and 'Motivational interest in mindfulness'. These themes emerged from the focus group results, as informed by research on stress and coping, and education literature related to learning motivation and educational structure (Becker, Geer, \& Hughes, 1968; Gardner, 1983; Lazarus \& Folkman, 1987; Gardner, 2010; Arum, 2011). Representative quotes and associated themes are included in Table I.

\section{Variation in stress experience}

Focus group participants found it easy to talk about their stressors. The ways in which participants experienced stressors varied, with comparable stressors elucidating stronger feelings of stress in some students compared to others. Students varied in the ways they appraised their stress, with sub-themes emerging as 'Low-Stress' and 'High-Stress' students. Sub-themes were assigned to quotes using brackets at the end of each quote.

Students who said they managed stress well attributed their experience to specific actions or activities, such as taking time for themselves and staying organised.

'See that's part of why I'm not as stressed, is because I'm pretty organised. I think after the exam on Monday I work every day, or every Monday but I think I kind of take that time, that Monday night for myself and then I start getting back into [the] studying grind Tuesday, Wednesday, Thursday...'

[Low Stress]

In contrast were students who reported a High-Stress experience. In some cases, High-Stress students reported acclimating to their stress experience, but realised that stress and associated behaviours may have some negative effects on their health.

'I think yeah... I've had a very stressful start'

'I feel like I may be stressed, but I'm just so adapted or acclimated to how much I need to do that I don't think that I'm stressed, but maybe inside my body, you know, who knows how healthy my body is because I'm drinking tons of coffee to keep me up, and I'm eating whatever's convenient.'

[High Stress]
Individuals who were experiencing high stress consistently reported engaging in more negative self-talk and had high expectations for their own productivity and performance. As such the sub-theme 'Negative-Self Talk' was assigned. In some instances, negative self-talk and judgement were accepted, provided they motivated the student to perform.

'Sometimes I do and when I'm really judgmental on myself, if I got a bad test score that I wasn't happy with, or a bad quiz score that I got, anything like that, I will be like, "Oh my god, you're awful."'

[High Stress, Negative Self-talk]

'Well, I guess if you're getting angry at yourself it helps motivate you to actually do something, like work out or something helpful, then I'd say it's okay. But otherwise I'd say it's not really that helpful."

[High Stress, Negative Self-talk]

\section{Appraising coping mechanisms}

The approaches to managing stress varied, with many students preferring stress management techniques associated with additional productivity. These activities were reported by students to be 'mindless' in nature, while simultaneously accomplishing non-academic tasks or goals (e.g. multitasking). Sub-themes of 'Mindless', 'Task-oriented', and 'Productivity' were assigned. Some students reported using coping mechanisms that brought temporary stress relief, but students noted the strategies ultimately were unhelpful, unproductive, or unhealthy. The sub-themes of 'Ineffective Coping', 'Unproductive', and 'Unhealthy Coping' were assigned to transcript segments where students felt their coping mechanisms fell short. In some instances, students were aware they currently participated in a number of activities or behaviours that were perceived to be a waste of time and wished they used that time more productively.

'Dishes and laundry. That's really mindless.'

[Mindless, Task-oriented, Productivity]

'Food. I don't know that it helps, but it makes me feel better'

[Ineffective, Unhealthy Coping]

'But now that I'm thinking about it, I waste so much time on my phone, so it's like, why can't I take the time and put it to something useful that would de-stress me...?'

[Unproductive]

In one instance, a student applied their anatomy lessons during a massage as a way of being academically productive during a time of relaxation. 
'So, for me when they were massaging [me], I was like, oh, they are doing my Sartorius muscle. I was like, ok, I know this. That worked for me.'

[Productivity]

\section{Motivational interest in mindfulness}

After discussing stress and coping mechanisms, students were presented with an adapted definition of mindfulness: 'Mindfulness is a practice of bringing complete attention to the present experience on $a$ moment-to-moment basis, non-judgmentally. Often one sits quietly, focusing on the breath experience'. Students were asked to discuss their initial reaction to mindfulness and its use as a stress coping strategy.

Overall students expressed interest in mindfulness, but mindfulness perceptions were clearly mixed. Students approached mindfulness with a sense of curiosity surrounding the benefits of mindfulness for stress relief, personal growth and how mindfulness could be used to improve self-awareness. The sub-themes of 'Mindfulness Perceptions-Positive' and 'Mindfulness Interest' were assigned to representative quotes.

'I think that probably... [mindfulness] sounds like a great way to relieve stress and remove yourself from the enormity of it all.'

[Mindfulness Perceptions - Positive, Mindfulness Interest]

'It interests me because will it allows me to just step away for a second? Like we were talking about, centre yourself and be aware of how I am reacting to something, and it will help me take action. Focus my goals and know what I want by being familiar with myself.'

[Mindfulness Perceptions - Positive, Mindfulness Interest]

While few students were opposed to the general idea of mindfulness and mindfulness oriented meditation, some shared personal stereotypes of persons who meditate using terminology like 'hippies'. Additionally, most students were aware that mindfulness may be perceived negatively by their peers or that the idea of mindfulness was associated with social stigma. The sub-theme of 'Mindfulness Perceptions - Negative' was assigned to representative quotes.

'...Y'know, far out, dude, when it comes to meditating...। literally just think of some guy sitting cross-legged on the floor.'

[Mindfulness Perceptions - Negative]

I feel like a lot of people are scared of it... because they don't really know what it is. It's like this foreign concept." [Mindfulness perceptions - Negative]
I'm not really sure, like, what else a stereotype is, but just like, I had someone that I asked to come today, and they said they didn't want to because it was about mindfulness.' [Mindfulness perceptions - Negative]

Students also perceived the goal of mindfulness to be the elimination of thoughts and completely clearing one's mind. This was counter to the definition of mindfulness presented, identifying the sub-theme of 'Mindfulness Misconceptions'.

\section{'Trying to empty your mind.'}

[Mindfulness Misconceptions]

While students expressed interest in mindfulness on a personal level, these statements were followed by skepticism as students began to talk about how busy they were and rationalising the use of time for other activities.

\section{The sub-themes of 'Busyness' and 'Mindfulness Hesitation'}

'I think it's hard not to be judgmental because you know you have so much other stuff to do, why should you take a five-minute break to be mindful if I know I have ten thousand other things I have to do.'

[Busyness, Mindfulness Hesitation]

When probed, students who expressed interest in mindfulness determined that the time may be better spent elsewhere or used in a way that was certain to provide benefit. Students reported willingness to try mindfulness or MOM if there was an evidence base supporting potential benefits.

'Especially making time for something that works, like I guess I'm hesitant to try something, like essentially waste the time if it doesn't work for me So I think if I found something that worked [to relieve stress] I would be likely to do it more often...'

[Busyness, Mindfulness Hesitation]

Students grew more interested in mindfulness as they evaluated potential benefits in a professional context and when explicit rewards or additional accreditation could be attained. The sub-themes of 'Mindfulness Benefit Evaluation' and 'Rationalisation' were assigned.

'I think that there would be a lot more interest if we were able to tie it back to what we'll be doing either in school or as a profession.'

[Mindfulness Benefit Evaluation, Rationalisation]

'Maybe a certificate or something like that with like a Health Coaching certificate that touched base with mindfulness, or something like that.'

[Mindfulness Benefit Evaluation, Rationalisation] 


\section{Discussion}

Overall, this study was successful in advancing the aim of evaluating the relationship between student stress and interest in exploring mindfulness as a potential stress coping mechanism. These data also aid in the understanding of how students appraise stress, the coping mechanisms used to manage stress, the effectiveness of these coping mechanisms, and interest in and awareness of mindfulness or MOM. Generally, students reported both low- and high-stress appraisal while reporting a variety of coping mechanisms that both did, and did not work. Students appraising their stress as low seemed less interested in mindfulness or MOM as a means of coping, but used terminology that suggest stress was still experienced. Phrases like 'studying grind' suggest that even students experiencing relatively low levels of stress are faced with discomfort and strenuous academic experiences.

Students frequently reported feelings of ongoing busyness which created conflict among participants as they weighed the potential benefits of MOM with other demands on their time. Students rationalised the use of mindfulness by evaluating the professional benefit, developing skills related to leadership and professional communication. Students were hesitant to identify with the personal benefits potentially associated with mindfulness and MOM. In many instances, students seemed to justify, hide, or reframe personal interest with professional performance improvement and ways they could differentiate themselves from their peers.

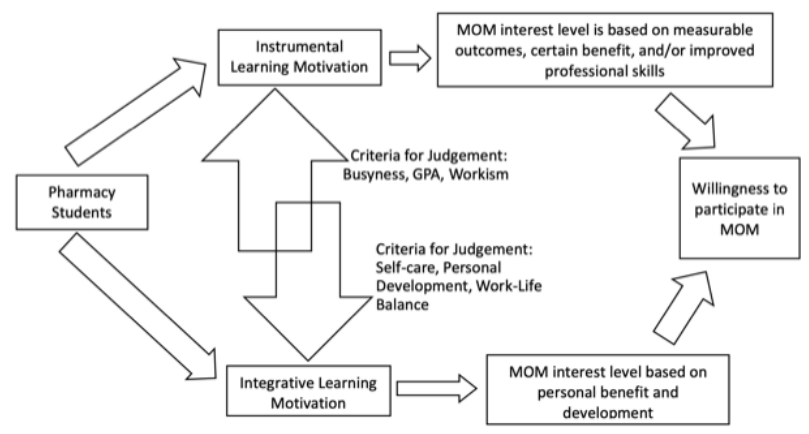

Figure A: Criteria for judgement and learning motivation influence on willingness to participate in MOM

Given the conflict between student stress and educational demands, concepts from educational theory and literature were used to help explain student behaviours and motivation to practice mindfulness or MOM within their academic context. Together, concepts from the Student's Academic Perspective (SAP) and Learning Motivation (Becker, Geer, \& Hughes, 1968; Gardner, 1983; Gardner, 2010; Arum, 2011) provide a framework for understanding student interest in MOM which is illustrated in Figure A. Using SAP and Learning Motivation, a number of recommendations can be made for colleges of pharmacy and other academic institutions to increase the use of mindfulness, MOM, and other self-care activities to improve stress-management and well-being.

\section{Appraisal and expectations of coping mechanisms in the Students' Academic Perspective (SAP)}

To understand the student experience with stress, coping mechanism appraisal behaviour, and willingness to engage in effective coping mechanisms such as MOM, the SAP can be considered. According to Becker and colleagues, students frame their academic experience using perspectives and goals (Becker, Geer, \& Hughes, 1968). Perspectives of the academic experience can be realised by considering the learner's definition of the situation, activities required or expected, and criteria for judgement (Becker, Geer, \& Hughes, 1968; Arum, 2011).

A student's definition of the situation is the set of ideas that describe the context of the academic experience, which inform students' evaluation and ability to distinguish between what is and is not important in their academic careers. Students implicitly understand the expectations of different professors and courses, decide what activities to pursue, and what behaviours to exhibit. Within pharmacy education, learners may define their situation by considering how they are assessed in class (e.g. grade-point average [GPA]) and what extracurriculars look attractive on a resume (e.g. professional organisations or research) to define their situation and pursue their goals. (Becker, Geer, \& Hughes, 1968; Arum, 2011).

Focus group results suggest the activities associated with well-being and stress management may not be a large component of their situational definition, that is, wellbeing and stress management may be personally important, but less important than other components of their academic careers. While pharmacy organisations and colleges of pharmacy have initiated conversations surrounding the importance of student mental health, well-being, and stress management, students may perceive these initiatives as a recommendation rather than an expectation. Colleges of pharmacy could reframe stress-management and well-being initiatives as 
expectations for students to meet, helping to incorporate well-being and stress-management into students' definition of their situation and goals.

The SAP also emphasises the concept of criteria for judgment which encompasses the standards by which the learner will evaluate their success, as well as how they will evaluate the success of others in comparison (e.g. GPA). (Becker, Geer, \& Hughes, 1968; Arum, 2011). Students perform activities and pursue goals based on how they define success, often using metrics for achievement like a GPA Perspective (Becker, Geer, \& Hughes, 1968; Arum, 2011) which produce tangible rewards, a sense of productivity, and a metric by which to compare one's own success to others. Focus group results suggest that while students were interested in managing their stress, stresslevels and well-being were not a criterion by which they evaluated their success or the success of others. Colleges of pharmacy should carefully consider the criteria for judgement their institution and students use to benchmark success and discern how these support or conflict with their values on personal development, mental health, well-being, and stress management.

\section{Learning motivations and MOM orientation}

With the SAP and student's criteria for judgement in mind, two learning motivation styles may be useful in explaining student motivation to practice mindfulness or MOM: 'instrumental' and 'integrative learning motivation' (Gardner, 1983; Gardner, 2010; Arum, 2011). Integrative motivation can be described as motivation that stems from the individual desire to integrate into a specific community or group (Gardner, 1983; Arum, 2011). In this case, integrative motivation would be focused on becoming an effective and impactful clinician within the profession of pharmacy. Individuals exhibiting this type of motivation display curiosity and learn for the sake of learning, tend to have more persistence in their learning, and are interested in developing the traits and skills required of them by their community (Hofmann \& Gómez, 2017).

Individuals with instrumental motivation are primarily motivated to learn by perceived utility of the information. Learners with instrumental motivation engage in learning activities with the purpose of pragmatic gains and achievements rather than group integration. For example, pharmacy students with instrumental motivation may focus on memorising medication details to perform successfully on an upcoming exam. Instrumental learners perform predominately for the purposes of attainment of external rewards rather than for holistic professional development (Gardner, 2010).

From focus group results, the majority of students seemed to initially show signs of integrative motivation by expressing interest in using mindfulness for personal and professional benefit in the context of stressful living and work environments and how these benefits can contribute to self-awareness, empathetic communication, stress-reduction, and overall well-being. While few students expressing integrative motivation were initially interested, students became more interested in mindfulness or MOM when pragmatic gains like a certificate of completion for engaging in a MOM programme was discussed, which is consistent with instrumental motivation.

The number of students experiencing higher levels of instrumental motivation toward learning may be a barrier to widespread student engagement with mindfulness, MOM, or other well-being and stress-management activities. MOM has few, if any, tangible and immediately observable effects, discouraging students with instrumental motivation from initiating and maintaining a mindfulness practice. Colleges of pharmacy should develop courses, initiatives, and incentives to encourage development of integrative motivation, but work to include students with instrumental motivation to participate with the hope they will increasingly adopt an integrative learning orientation. This is increasingly relevant as professional burnout continues to rise and resilience, empathy, and self-awareness are seen as increasingly valuable,

\section{Summary of recommendations}

Based on the results of this study there are a number of potential recommendations. Colleges of pharmacy should reframe stress-management and well-being initiatives as expectations for students to meet, helping to incorporate well-being and stress-management into students' definition of their situation and criteria for judgement, along the same lines as GPA and organisational involvement. This can be done by helping students evaluate how mindfulness, MOM, and other self-care activities relate to their academic and professional goals. Lastly, colleges of pharmacy should develop courses, initiatives, and incentives to encourage development of integrative learning motivation. Doing so may help students with instrumental motivation broaden their perspectives and potentially become more effective as practicing pharmacists. 


\section{Strengths and limitations}

This study used existing theories and concepts from the educational literature to guide thematic analysis and data interpretation. Additionally, data collection and analysis were performed following the Consolidated Criteria for Reporting Qualitative Studies (COREQ) guidelines to ensure quality of data collection and reporting. As such, it is important to disclose the positionality of the authors within the context of this work to facilitate transparency. Both researchers are licensed pharmacists associated with a health services research department of a researchintensive pharmacy college. Both have formal qualitative research training through graduate-level coursework. Both authors have read extensively on MOM and have developed a personal MOM practice. To address potential bias arising from positionality, a standardised definition of MOM was used to describe the practice to student pharmacists during focus groups and students were not made aware that the study authors had previous experience with MOM or had developed personal practices (Tong, Sainsbury, \& Craig, 2007).

This work should be considered exploratory given the number of participants and cross-sectional design. Student schedules meant only a fraction of students were able to join a focus group. Other students at the study college may have different experiences and ideas. While some participants did seem open to mindfulness, participants shared a range of perspectives. Deeper oneon-one interviews may be useful in understanding what experiences in someone's life may contribute to their own stress and coping emotions, cognitions, and behaviours. Students at other colleges, with other curricular designs, and in other geographic areas in the US and internationally may have differing perspectives.

\section{Future Research}

Future work should focus on further exploring and validating the proposed associations between learning motivation, components of the student's academic perspective, and willingness to practice mindfulness or MOM and other activities that classify as self-care for the purposes of decreasing stress, improving well-being, and increasing resilience in pharmacy students. This could include measure of development and validation to operationalise these concepts for pharmacy education. Additionally, the effect of student environment, nature of the pharmacy curriculum, institutional structure on student stress and well-being should be explored and quantified.

\section{Conclusions}

In this focus group study of student pharmacists, participants had a range of stress experiences and stress management practices. Students assigned relatively little value to coping strategies perceived as having an ambiguous certainty of benefit, especially when those activities may not facilitate goal attainment, align with their academic perspective, or learning motivation. Students were generally interested in participating in elective course work focusing on mindfulness, especially when tangible benefits were discussed. In order to justify their participation in self-care activities such as mindfulness or MOM, students needed to establish that the activity would align with their professional motivations and be associated with positive criteria for judgement. As such, there are a number of considerations that should be made by colleges of pharmacy to improve student wellbeing, mental health, and stress-management.

\section{References}

Arum, R. (2011). Academically adrift:limited learning on college campuses. Chicago: University of Chicago Press. https://doi.org/ 10.7208/chicago/9780226028576.001.0001

Awe, C., Gaither, C.A., Crawford, S.Y., \& Tieman, J.A. (2016). Comparative Analysis of Perceptions of Pharmacy Students' Stress and Stressors across Two Multicampus Universities. American Journal of Pharmaceutical Education, 80(5), 82. https://doi.org/10.5688/ajpe80582

Beall, J.W., DeHart, R.M., Riggs, R.M., \& Hensley, J. (2015). Perceived Stress, Stressors, and Coping Mechanisms among Doctor of Pharmacy Students. Pharmacy (Basel, Switzerland), 3(4),344-354. https://doi.org/10.3390/pharmacy3040344

Becker, H.S., Geer, B., \& Hughes, E.C. (1968). Foundations of Higher Education. Making the Grade: The Academic Side Of College Life Piscataway, NJ, US: Transaction Publishers

Chisholm-Burns, M.A., Spivey, C.A., Jaeger, M.C., \& Williams, J. (2017). Associations Between Pharmacy Students' Attitudes Toward Debt, Stress, and Student Loans. American Journal of Pharmaceutical Education, 81(7), 5918-5918. https://doi.org/ 10.5688/ajpe8175918

Crescentini, C., Capurso, V., Furlan, S., \& Fabbro, F. (2016). Mindfulness-Oriented Meditation for Primary School Children: Effects on Attention and Psychological Well-Being. Frontiers in Psychology, 7(805). https://doi.org/10.3389/fpsyg.2016.00805

Durham, M.E., Bush, P.W., \& Ball, A.M. (2018). Evidence of burnout in health-system pharmacists. American Journal of Health-System Pharmacy, 75(23, Sup.4): S93-s100. https:// doi.org/10.2146/ajhp170818

Economides, M., Martman, J., Bell, M.J., \& Sanderson, B. (2018). Improvements in Stress, Affect, and Irritability Following Brief Use of a Mindfulness-based Smartphone App: A Randomized Controlled Trial. Mindfulness, 9, 1584-1593. https://doi.org/ $\underline{10.1007 / \mathrm{s} 12671-018-0905-4}$ 
Gardner, R.C. (1983). Learning another language: A true social psychological experiment. Journal of Language and Social Psychology, 2(2-3-4), 219-239. https://doi.org/10.1177/0261927 $\underline{\mathrm{X} 8300200209}$

Gardner, R.C. (2010). Motivation and second language acquisition: The socio-educational model. Peter Lang Inc.

Heeter, C., Lehto, R., Allbritton, M., Day, T., \& Wiseman, M. (2017). Effects of a Technology Assisted Meditation Program on Healthcare Providers' Interoceptive Awareness, Compassion Fatigue, and Burnout. Journal of Hospice \& Palliative Nursing 19(4), 314-322. https://doi.org/10.1097/NJH.0000000000000349

Hofmann, S.G., \& Gómez, A.F. (2017). Mindfulness-Based Interventions for Anxiety and Depression. Psychiatric Clinics of North America, 40(4), 739-749. https://doi.org/10.1016/i.psc. $\underline{2017.08 .008}$

Huijsmans, I., Ma, I., Micheli, L., Civai, C., Stallen, M., \& Sanfey, A.G. (2019). A scarcity mindset alters neural processing underlying consumer decision making. Proceedings of the National Academy of Sciences of the U.S.A. 116(24), 11699-11704. https://doi.org/10.1073/pnas.1818572116

Jones, G.M., Roe, N.A., Louden, L., \& Tubbs, C.R. (2017). Factors Associated With Burnout Among US Hospital Clinical Pharmacy Practitioners: Results of a Nationwide Pilot Survey. Hospital Pharmacy. 52(11), 742-751. https://doi.org/10.1177/001857871 $\underline{7732339}$

Kabat-Zinn, J. (1994). Wherever you go, there you are: Mindfulness meditation in everyday life. New York: Hyperion

Lamothe, M., Rondeau, É., Malboeuf-Hurtubise, C., Duval, M., \& Sultan, S. (2016). Outcomes of MBSR or MBSR-based interventions in health care providers: A systematic review with a focus on empathy and emotional competencies. Complementary Therapies in Medicine. 24, 19-28. https://doi. org/10.1016/j.ctim.2015.11.001

Lazarus, R.S., \& Folkman, S. (1987). Transactional theory and research on emotions and coping. European Journal of Personality, 1(3), 141-169. https://doi.org/10.1002/per. $\underline{2410010304}$

Luthans, F., Vogelgesang, G.R., \& Lester, P.B. (2006). Developing the Psychological Capital of Resiliency. Human Resource Development Review, 5(1), 25-44. https://doi.org/10.1177/15 $\underline{34484305285335}$

Mantzourani, E., Desselle, S., Le, J., Lonie, J.M., \& Lucas, C. (2019). The role of reflective practice in healthcare professions: Next steps for pharmacy education and practice. Research in Social and Administrative Pharmacy, 15(12), 1476-1479. https:// doi.org/10.1016/i.sapharm.2019.03.011

Marshall, L.L., Allison, A., Nykamp, D., \& Lanke, S. (2008). Perceived stress and quality of life among doctor of pharmacy students. American Journal of Pharmaceutical Education, 72(6), 137. https://doi.org/10.5688/aj7206137

Matheson, C., Robertson, H.D., Elliott, A.M., Iversen, L., \& Murchie, P. (2016). Resilience of primary healthcare professionals working in challenging environments: a focus group study. British Journal of General Practice, 66(648), e507-515. https://doi.org/10.3399/bjgp16X685285
McConville, J., McAleer, R., \& Hahne, A. (2017). Mindfulness Training for Health Profession Students-The Effect of Mindfulness Training on Psychological Well-Being, Learning and Clinical Performance of Health Professional Students: A Systematic Review of Randomized and Non-randomized Controlled Trials. Explore (NY), 13(1), 26-45. https://doi.org/ 10.1016/j.explore.2016.10.002

Morrison Wylde, C., Mahrer, N.E., Meyer, R.M.L., \& Gold, J.I. (2017). Mindfulness for Novice Pediatric Nurses: Smartphone Application Versus Traditional Intervention. Journal of Pediatric Nursing, 36, 205-212. https://doi.org/10.1016/j.pedn. $\underline{2017.06 .008}$

O'Driscoll, M., Byrne, S., Kelly, M., Lambert, S., \& Sahm, L.J. (2019). A Thematic Analysis of Pharmacy Students' Experiences of the Undergraduate Pharmacy Degree in Ireland and the Role of Mindfulness. American Journal of Pharmaceutical Education, 83(1), 6457. https://doi.org/10.5688/ajpe6457

O'Driscoll, M., Byrne, S., McGillicuddy, A., Lambert, S., \& Sahm, L.J. (2017). The effects of mindfulness-based interventions for health and social care undergraduate students - a systematic review of the literature. Psychology, Health \& Medicine, 22(7), 851-865. https://doi.org/10.1080/13548506.2017.1280178

Opoku-Acheampong, A., Kretchy, I.A., Acheampong, F., et al. (2017). Perceived stress and quality of life of pharmacy students in University of Ghana. BMC Research Notes, 10(115). https:// doi.org/10.1186/s13104-017-2439-6

Pospos, S., Young, I.T., Downs, N., Iglewicz, A., Depp, C., Chen, J.Y., Newton, I., Lee, K., Light, G.A., \& Zisook, S. (2018). WebBased Tools and Mobile Applications To Mitigate Burnout, Depression, and Suicidality Among Healthcare Students and Professionals: A Systematic Review. Academic Psychiatry, 42(1), 109-120. https://doi.org/10.1007/s40596-017-0868-0

Schommer, J.C., Gaither, C.A., Goode J.-V.K.R., Owen, J.A., Scime, G.M., Skelton, J.B., Cernasev, A., \& Hillman, L.A. (2019). Pharmacist and Student Pharmacist Views of Professional and Personal Wellbeing and Resilience. Journal of American Pharmacy Association, 60(1), 47-56. https://doi.org/10.1016/ j.japh.2019.09.006

Silva, R.G., \& Figueiredo-Braga, M. (2018). Evaluation of the relationships among happiness, stress, anxiety, and depression in pharmacy students. Current in Pharmacy Teaching \& Learning, 10(7), 903-910. https://doi.org/10.1016/i.cptl.2018.04.002

Thomas, D.R. (2006). A General Inductive Approach for Analyzing Qualitative Evaluation Data. American Journal of Evaluation, 27(2), 237-246. https://doi.org/10.1177/1098214005283748

Tong, A., Sainsbury, P., \& Craig, J. (2007). Consolidated criteria for reporting qualitative research (COREQ): a 32-item checklist for interviews and focus groups. International Journal for Quality in Health Care, 19(6), 349-357. https://doi.org/10.1093/intahc/mzm042

Tsingos, C., Bosnic-Anticevich, S., \& Smith, L. (2014). Reflective practice and its implications for pharmacy education. American Journal of Pharmaceutical Education. 78(1), 18. https://doi.org/ 10.5688/ajpe78118

van der Riet, P., Levett-Jones, T., \& Aquino-Russell, C. (2018). The effectiveness of mindfulness meditation for nurses and nursing students: An integrated literature review. Nurse Education Today, 65, 201-211. https://doi.org/10.1016/i.nedt.2018.03.018 
Witry, M.J., Murry, L.T., \& Ray, M.E. (2020). Considerations for the incorporation of mindfulness into pharmacy education. Currents in Pharmacy Teaching \& Learning. 12(3), 247-250. https://doi.org/10.1016/i.cptl.2019.12.007

Yang, E., Schamber, E., Meyer, R.M.L., \& Gold, J.I. (2018). Happier Healers: Randomized Controlled Trial of Mobile Mindfulness for Stress Management. The Journal of Alternative and Complementary Medicine. 24(5), 505-513. https://doi.org/ $\underline{10.1089 / \mathrm{acm} .2015 .0301}$

\section{Appendix A}

\section{Mindfulness Focus Group Guide}

Participants Female Class

What do you do to manage school-related stress? [How is that working?]

How many of you know someone that meditates? [Celebrity?] [How?]

What do you know about mindfulness meditation?

Definition: Mindfulness is a practice of bringing complete attention to the present experience on a moment-to-moment basis, non-judgmentally. Often one sits quietly, focusing on the breath experience.

What thoughts or reactions do you have to a definition like this?

Does this idea interest you? Why or why not?

What do you think about people that meditate?

What concerns or barriers do you see to yourself meditating?

Generally, people learn Mindfulness from a group session led by an instructor over multiple weeks. How much interest do you have in a course on mindfulness?

What else in addition to or instead of a course may be of interest related to this topic? 